\title{
Investigação de paternidade na ausência do suposto pai
}

\author{
Paternity testing father is absent
}

Silvia O. SAMPAIO'; J.R.R. PINHO'; C.B. GRANJA3; A.C. GOLDBERG ${ }^{4}$

SAMPAIO, S.O.; PINHO, J.R.R.; GRANJA, C.B.; GOLDBERG, A.C. Investigação de paternidade na ausência do suposto pai. Saúde, Ética \& Justiça, 5/7(1-2):6-11, 2000-2002.

Resumo: Este artigo tem por objetivo esclarecer os profissionais que trabalham com processos de Investigação de Paternidade sobre os testes de DNA (Southern blot ou PCR) disponíveis no mercado, bem como orientar a escolha dos indivíduos que devem ser convocados para o teste de DNA na ausência do suposto pai. A técnica de PCR é menos trabalhosa, permite maior reprodutibilidade dos resultados entre diferentes laboratórios, sendo a técnica de escolha para exames de paternidade quando se dispõe do material genético do suposto pai. Por outro lado, esta técnica analisa locos com menor número de alelos, podendo levar a resultados inconclusivos quando a investigação é realizada na ausência do suposto pai. Nestes casos, a técnica de Southern blot é indicada, pois analisa regiões cromossômicas com maior polimorfismo genético, devendo-se analisar o maior número possível de supostos tios e/ou supostos irmãos com as suas respectivas mães.

Unitermos: Paternidade. Reação em cadeia de Polimerase/métodos. DNA/genética. Repetições mini-satélites/genética. Southern Blotting/métodos.

1. Médica Patologista Clínica, perita em Investigação de Paternidade no Laboratório Bioquímico Jardim Paulista. Doutora em Imunologia pela Universidade de São Paulo.

2. Médico Patologista Clínico, perito em Investigação de Paternidade e responsável técnico pelos testes de Paternidade no Laboratório Bioquímico Jardim Paulista. Doutor em Bioquímica pela Universidade de São Paulo.

3. Médica especialista em tipagem HLA por Biologia Molecular. Doutora em Imunologia pela Universidade de São Paulo.

4. Bióloga responsável pelo setor de Biologia Molecular do Laboratório de Imunologia de Transplantes, InCor-FMUSP. Livre Docente em Imunologia pela Universidade de São Paulo.

Endereço para correspondência: Bioquímico Jardim Paulista - Análises Clínicas Centro de Diagnósticos. Dra. Sílvia Sampaio. Av. Brigadeiro Luiz Antônio, 4701, CEP 01401-002. São Paulo, SP, Brasil. 
$\mathrm{T}$ oda a informação necessária para elaboração dos produtos funcionais (proteínas) que compõem o ser vivo encontra-se armazenada no núcleo da célula, na forma de ácido desoxiribonucléico, o DNA. O DNA está distribuído em unidades chamadas cromossomos. Os seres humanos normais possuem 46 cromossomos, 23 herdados do pai e 23 herdados da mãe. A investigação de paternidade baseia-se na determinação de um vínculo genético (do grego genetikós: "que engendra", "que produz") entre duas ou mais pessoas. Este vínculo é definido pelo conteúdo individual de DNA e pode ser estabelecido através da análise de características específicas que funcionam como marcadores genéticos.

Algumas características individuais podem ser facilmente detectadas (cor de olhos, cabelos e pele). No entanto, este tipo de identificação individual dificilmente será informativa, dada a universalidade destes marcadores. Outras características, como tipo sangüíneo, exigem testes laboratoriais específicos.

No início do século, a descoberta das proteínas que compõem os grupos sangüíneos $A B O$ foi $o$ primeiro passo para a análise da investigação de paternidade. Estas proteínas apresentam pequenas variações que podem ser identificadas através de exames laboratoriais relativamente simples. A identificação destas proteínas permite distinguir grupos de indivíduos portadores da mesma variante protéica, funcionando como mais um valioso marcador genético. A análise conjunta dos grupos sangüíneos $A B O$, Rh e de outros grupos como MNS, Duffy, Kidd, Lewis permitia a exclusão de paternidade com percentual de aproximadamente $90 \%$.

Posteriormente, em 1948, o Prof. Jean Dausset descreveu as proteínas extremamente diversificadas do sistema HLA, levando ao desenvolvimento de testes de investigação de paternidade a resultados bastante satisfatórios, com probabilidade de paternidade de $95-99 \%$, que começaram a ser utilizados na década de 80 .

Atualmente, o teste de escolha para a investigação de paternidade é a análise direta do material genético, ou seja, o DNA. Este teste analisa regiões do DNA que variam nos diferentes indivíduos de uma população. Há alguns anos, foram descritas regiões repetitivas do DNA humano que se caracterizam por uma variação no seu tamanho. Estas regiões, denominadas VNTR (do inglês: Variable Number of Tandem Repeats), podem ser observadas em diferentes cromossomos. Cada indivíduo possui um conjunto único destas variantes, sendo a metade proveniente da mãe e a outra metade do pai.

A análise das regiões VNTR pode ser feita através de técnicas distintas, como hibridização (Southern blot) ou PCR (Reação em Cadeia da Polimerase), que permitem medir com precisão o segmento de DNA que contém a seqüência VNTR estudada. Na técnica de Southern blot, ou RFLP (do inglês, Restriction Fragments Length Polymorphism) estes segmentos são visualizados como bandas negras no filme de raio $X(R X)$. A Figura 1 mostra as diversas bandas observadas quando analisamos uma região VNTR de 9 indivíduos não-relacionados. Cada indivíduo possui dois segmentos VNTR (dois alelos), um herdado da mãe e outro do pai. Alguns indivíduos, como é o caso da amostra 7, herdam segmentos do mesmo tamanho e neste caso visualizamos uma única banda no RX. O marcador de peso molecular (M) permite calcular o tamanho dos fragmentos analisados.

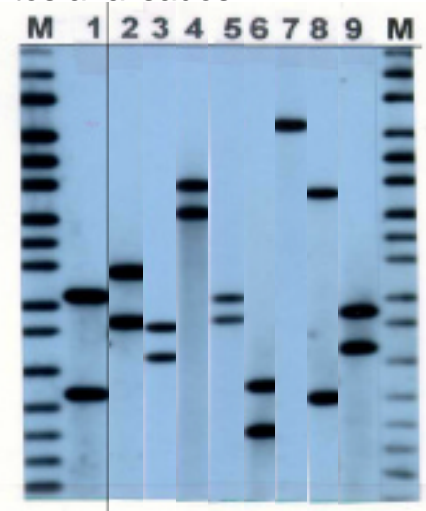

Figura 1 - A análise de uma região VNTR do cromossomo 1 (D1S7) pela técnica de Southern blot. A figura mostra a análise de 9 indivíduos não relacionados. $\mathrm{M}=$ marcador de peso molecular 
SAMPAIO, S.O. et al. Investigação de paternidade na ausência do suposto pai.

A técnica de PCR permite produzir milhões de cópias específicas de DNA. Uma limitação desta técnica é o tamanho do fragmento a ser amplificado. Por este motivo, utilizam-se regiões VNTR menores denominadas STR (Small Tandem Repeats). Os fragmentos amplificados podem ser analisados em seqüênciadores automáticos de DNA. Também neste caso identificamos dois fragmentos em cada indivíduo (Figura 2).
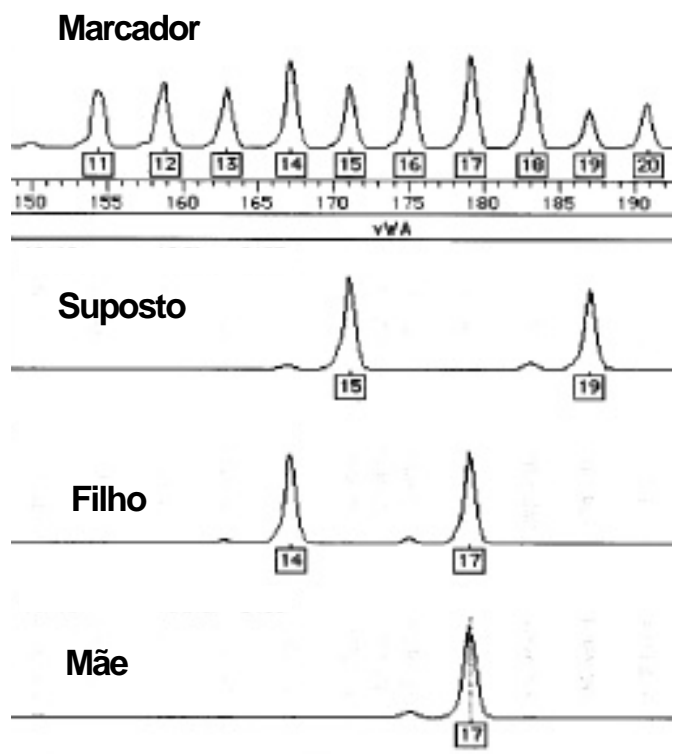

Figura 2 - A análise de uma região STR (vWA) pela técnica de PCR. O marcador alélico (primeira linha) permite identificar os alelos observados no suposto pai (segunda linha), no filho (terceira linha) e sua respectiva mãe (quarta linha)

No caso mais comum, quando dispomos de material do suposto pai, mãe e filho, a análise se inicia pela comparação dos segmentos VNTR do filho com os da mãe. Os dois indivíduos compartilham necessariamente um alelo, permitindo que o segmento VNTR herdado do pai (alelo paterno) seja identificado por exclusão. A Figura 3 mostra a análise de uma região VNTR em dois casos de investigação de paternidade. Os segmentos VNTR da mãe (coluna 1) são visualizados ao lado dos segmentos VNTR do filho (coluna 2). $\mathrm{O}$ alelo paterno, ou seja, o alelo não compartilhado com a mãe é facilmente identificado (indicado por uma seta). O pai biológico deverá apresentar um segmento VNTR do mesmo tamanho do alelo paterno identificado no filho (Figura 3A, coluna 3). Quando o suposto pai não apresenta um segmento VNTR idêntico ao alelo paterno (Figura 3B, coluna 3), levanta-se a hipótese de que o indivíduo não seja o pai biológico. Porém, exclusão de paternidade só pode ser confirmada quando observada em pelo menos dois cromossomos distintos, afastando-se desta forma um resultado falso devido a uma mutacão (alteracão do DNA) ocasional.
A

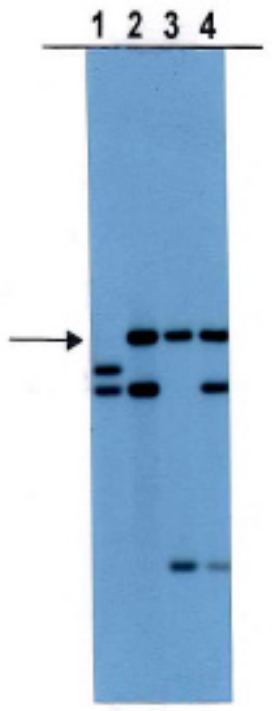

B

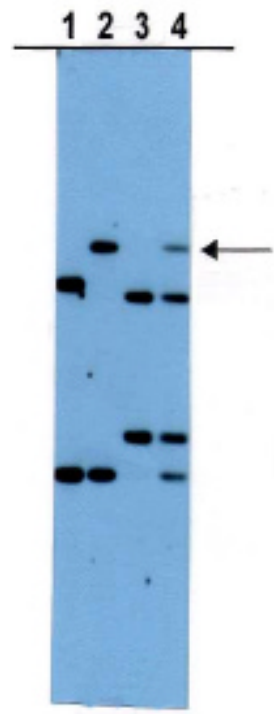

Figura 3 - Análise de uma região VNTR em dois casos de investigação de paternidade. Nos casos (A) e (B) analisamos o DNA da mãe (1), do respectivo filho (2) e do suposto pai (3). A linha 4 contém DNA do filho e do suposto pai. Em (A) o suposto pai não pode ser excluído como pai biológico e em (B) não observamos vínculo genético entre o filho e o suposto pai. A seta indica 0 alelo paterno (não compartilhado com a mãe)

Havendo a identidade entre o alelo paterno identificado no filho e um dos alelos do suposto pai (Figura 3A), calcula-se o Índice de Paternidade (IP). Este índice é calculado com base no Teorema de Bayes $^{1}$ que compara as chances do filho herdar o alelo compartilhado com o suposto pai - $50 \%$, quando o suposto pai possui 2 alelos distintos, ou 
$100 \%$ quando possui apenas $1 \mathrm{com}$ a freqüência deste alelo na população. Neste caso, como o pai possui 2 alelos distintos, utiliza-se a fórmula: IP = 0,5 (freqüência do alelo paterno na população). Dito de outra forma, o índice de paternidade referente a um suposto pai será tanto maior quanto mais raro for aquele alelo na população em geral. Depreendese deste fato a necessidade de se conhecer o perfil dos alelos na população a qual o suposto pai pertence. Vários estudos foram realizados para determinar a freqüência dos segmentos VNTR em diferentes populações, inclusive no Brasil ${ }^{2,3,4}$.

O índice de paternidade obtido com a análise de uma única região VNTR é insuficiente para determinação do vínculo genético. Assim, são analisadas diversas regiões VNTR ( 4 a 8 pela técnica de Southern blote 10 a 12 pela técnica de PCR). $O$ Índice de Paternidade Combinado (IPC), obtido através da multiplicação dos índices de paternidade de cada região examinada, permite calcular a probabilidade de paternidade (PP = IPC , IPC + 1). Uma probabilidade de paternidade acima de $99,8 \%$ permite confirmar com segurança a existência de um vínculo de paternidade ${ }^{5}$.

Quando o suposto pai investigado é falecido, pode-se realizar a investigação de paternidade utilizando-se o material genético de seus parentes de primeiro grau. A análise das regiões VNTR dos pais, irmãos ou filhos (reconhecidos legalmente) visa reconstituir o perfil genético do suposto pai. No primeiro caso, a análise consiste em comparar o alelo paterno do filho investigado com os alelos presentes nos supostos avós (Figura 4). No caso de inclusão, quando é confirmado o vínculo genético entre o suposto pai e o filho, deve haver identidade entre 0 alelo paterno e pelo menos 1 dos 4 segmentos VNTR identificados nos supostos avós (Figura 4, colunas 3 e 4). Como neste caso o Índice de Paternidade sofre uma redução importante: $\mathrm{IP}=$ 0,25 (chances do neto herdar 1 dos 4 alelos dos avós) (freqüência do alelo paterno na população), a análise de um número maior de cromossomos pode ser necessária para se obter um IPC aceitável.

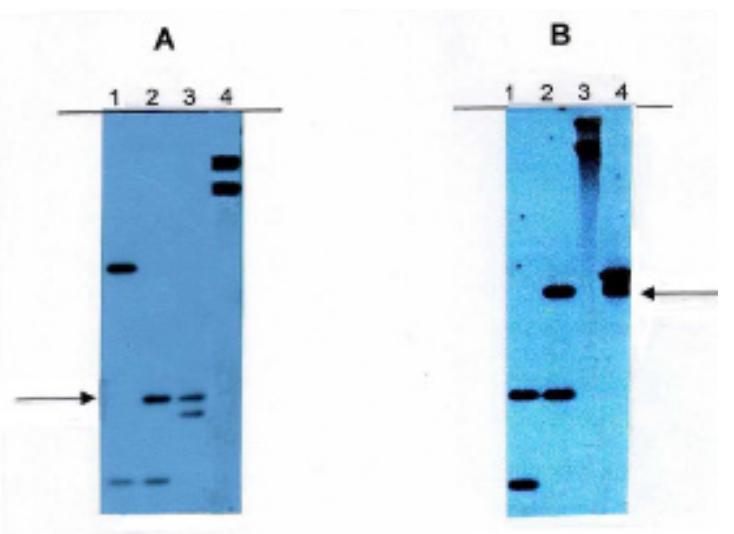

Figura 4 - Investigação do vínculo genético entre filho e supostos avós. Os DNAs da mãe (1), respectivo filho (2), suposta avó (3), e suposto avô (4) foram analisados em duas regiões VNTR localizadas no cromossomo $8(A)$ e cromossomo 4 (B). A seta indica o alelo paterno compartilhado com a suposta avó (A) e com o suposto avô (B).

Quando a investigação de paternidade é realizada apenas com irmãos do suposto pai (pelo menos dois), a análise pode resultar inconclusiva. Se houver identidade entre o alelo paterno e um dos alelos identificados nos supostos tios, calcula-se o IP = 0,25 (freqüência do alelo paterno na população). A exclusão, no entanto, só poderá ser indicada se forem revelados 4 alelos distintos nos supostos tios, pois neste caso temos a certeza de que ambos alelos do suposto pai foram identificados. A análise de um número maior de irmãos do suposto pai ou de um dos supostos avós deve aumentar as chances de um resultado conclusivo.

Quando o teste é realizado com filhos legítimos do suposto pai, a identificação do alelo paterno, deduzida a partir da análise paralela da(s) respectivas mãe(s), deve permitir a identificação de pelo menos um alelo do pai investigado (Figura 5). Assim, nas regiões onde for observada identidade entre os alelos paternos dos supostos meio-irmãos, o IP é calculado normalmente (IP $=0,5$ freqüência do alelo paterno). À semelhança do que foi discutido na análise de supostos tios, a exclusão só poderá ser indicada quando forem revelados os dois alelos do suposto pai investigado e a exclusão for caracterizada em pelo menos 2 cromossomos distintos. No 
SAMPAIO, S.O. et al. Investigação de paternidade na ausência do suposto pai.

caso mostrado na Figura 5A, o único alelo revelado do suposto pai não é compartilhado com o filho investigado. Este resultado isolado seria inconclusivo. De fato, quando analisamos no mesmo caso uma segunda região cromossômica (Figura 5B), os dois alelos do suposto pai são revelados (Figura 5B, coluna 4,5 e 6 ) e um deles tem identidade com o alelo paterno (Figura 5B, coluna 2) do filho.

$\mathrm{Na}$ ausência da mãe biológica dos supostos meio-irmãos, a interpretação dos resultados e o cálculo do Índice de Paternidade podem apresentar dificuldades. Mais uma vez, à semelhança do que foi discutido na investigação de supostos tios, os filhos do suposto pai podem apresentar 2, 3 ou 4 alelos distintos. Apenas neste último caso o perfil genético do suposto pai é revelado com segurança para se caracterizar uma exclusão, mas nas regiões onde houver identidade entre pelo menos um alelo dos meio-irmãos e o alelo paterno, o IP
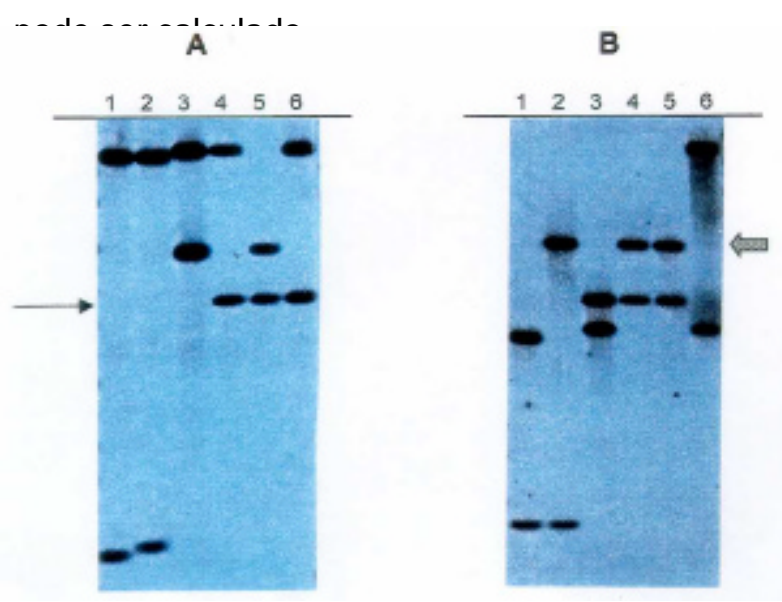

Figura 5 - Investigação do vínculo genético entre filho e supostos meio-irmãos. Os DNAs da mãe (1), respectivo filho (2), mãe dos supostos meio-irmãos (3), e três supostos meio-irmãos (4, $5,6)$ foram analisados em duas regiões VNTR localizadas no cromossomo 7 (A) e cromossomo 4 (B). Em (A) identificamos somente um alelo paterno $(\rightarrow)$ nos supostos meio-irmãos. Em (B), o alelo paterno dos meio-irmãos é compartilhado com o filho $(\Rightarrow)$.

O desenvolvimento da técnica de PCR possibilitou um grande avanço nas investigações de paternidade realizadas com material exumado. Esta técnica permite que as análises sejam realizadas com pequenas quantidades de DNA, mesmo que este apresente um certo grau de degradação. A análise direta do material genético do suposto pai é sempre a primeira escolha. No caso de supostos pais falecidos, o custo elevado dos procedimentos de exumação e as dificuldades técnicas encontradas na obtenção de DNA de alguns destes casos, tornam muitas vezes inviável a obtenção de um resultado conclusivo. Nos testes realizados com parentes de primeiro grau do suposto pai, a técnica de hibridização descrita neste artigo permite a obtenção de melhores resultados, pois as regiões VNTR analisadas apresentam uma maior variabilidade na população.

Familiares afastados por motivos diversos como guerras, adoção ou imigração têm originado um aumento no número de solicitações laboratoriais para determinação de vínculos genéticos. Alguns destes casos contam com apenas duas pessoas para a realização do teste. Por esse motivo, estudos visando o aprimoramento de novos métodos de análise genética para definição de parentesco continuam sendo numerosos na literatura internacional ${ }^{6}$.

Em conclusão, em investigações de paternidade realizadas através do DNA, a técnica de PCR apresenta a vantagem de ser tecnicamente menos trabalhosa e de permitir uma maior reprodutibilidade dos resultados, tornando possível a comparação entre diferentes laboratórios. Por outro lado, a técnica de análise do VNTR por hibridização ainda continua a ser a metodologia mais adequada a ser aplicada em casos de investigação de vínculo genético quando o suposto pai não pode ser analisado. Neste caso, aconselha-se que o DNA do filho e de sua mãe biológica sejam analisados juntamente com o material genético obtido de parentes de primeiro grau do suposto pai e que um maior número de regiões cromossômicas sejam estudadas. A análise dos supostos avós garante um resultado conclusivo mesmo na ausência da mãe biológica. Quando os supostos avós não podem ser estudados, deve-se reunir o maior número possível de supostos tios (irmãos do suposto pai) e/ou supostos irmãos (filhos reconhecidos do suposto pai). Neste último caso, a análise conjunta das respectivas mães garante um resultado conclusivo. 
SAMPAIO, S.O.; PINHO, J.R.R.; GRANJA, C.B.; GOLDBERG, A.C. Paternity testing father is absent. Saúde, Ética \& Justiça, 5/7(1-2):6-11, 2000-2002.

Abstract: The aim of this paper is to clarify the professionals involved in Paternity Testing on the different DNA assays currently available (Southern blot or PCR), and focusing specially on the choice of other relatives that should be analyzed if the alleged father is absent. PCR is less cumbersome, allows better reproductibility among results from different laboratories and is indicated when DNA from the alleged father is avaiable. On the other hand, this technique analyzes loci with fewer alleles and may lead to inconclusive results when the DNA from the alleged father cannot be obtained. In these cases, Southern blot should be utilized because in this technique more polymorphic chromossom regions are analyzed. In addition, analysis of the highest possible number of alleged uncles/aunts and alleged brothers/sisters, preferentially envolving also their mothers, is highly recommended.

Keywords: Paternity. Polymerase chain reaction/methods. DNA / genetics. Minisatellite. Repeats / genetics. Blotting, southern / methods.

\section{Referências}

1. Berry, D.A. Statistical issues in DNA identification. In: Billings, P. R., ed. DNA on trial. Cold Spring Harbor: CSHL Press, 1992. p.91-108.

2. Publication of Federal Bureau of Investigation 1993. VNTR population data: a worldwide study. Quantico, Virginia: Forensic Science Research and Training Center, FBI Academy, 1993.

3. Moura-Neto, R.S.; Silva, R.; Carvalho, E.F.; Zorio, D.R. Comparison of Rio de Janeiro DNA typing data with the FBI worldwide study. Ciên. Cult., 45(3/4):2582,1993 .
4. Moura-Neto, R.S.; Budowle, B. Fixed bin population data for the VNTR loci D1S7, D2S44, D4S139, D5S110, D10S28, and D14S13 in a population sample from Rio de Janeiro, Brazil. J. Forensic Sci., 42(5):9268, 1997.

5. Verbal Predicates, according to American Medical Association e American Bar Association guidelines Family Law Q., 10:3, 1976.

6. Wenk, R.E., Traver, M., Chiafari, F.A. Determination of sibship in any two persons. Transfusion, 36:25962, 1996. 